\title{
An experimental study of the behaviour of two rockfills accounting for the effects of degree of saturation
}

\author{
Roberta Ventini ${ }^{1, *}$, Alessandro Flora $^{1}$, Stefania Lirer $^{2}$, Claudio Mancuso ${ }^{1}$ and Antonio Cammarota ${ }^{1}$ \\ ${ }^{1}$ Federico II University, Department of Civil, Architectural and Environmental Engineering, 80125 Naples, Italy \\ ${ }^{2}$ Guglielmo Marconi University, Sustainability Engineering Department, 00193 Rome, Italy
}

\begin{abstract}
Rockfill dams have become more and more recognized for their safety, economy and adaptability to widely varying site conditions. As a contribution to the understanding of the main factors affecting the rockfill behaviour, the paper reports and discusses experimental data on several aspects relevant to the interpretation and analysis of their in-situ response. The experimental programme involved three series of oedometric tests on specimens of two different gravels having the same grading, reconstituted at the same initial relative density. Experimental observations on rockfills compressibility are presented and discussed: attention is paid to the role of degree of saturation $\left(\mathrm{S}_{\mathrm{r}}\right)$ through the analysis of "driest", "fully saturated" conditions, and the transition from one to the other. Grain crushing tests on dry and saturated soil particles are also reported. Grain size distributions of the specimens, both after compaction and after the oedometer tests, are compared in the paper. The results show that the effect of $S_{\mathrm{r}}$ cannot be overlooked in the mechanical characterization of the material, especially in rockfill/stress conditions prone to crushing.
\end{abstract}

\section{Introduction}

Rockfill materials are commonly used in the construction of many civil structures such as roads, railway embankments and earth and rockfill dams. The availability of coarse gravelly deposits and rock quarries makes strong interest in these structures. In fact, locally available materials make rockfill structures economical as well. Furthermore, the interest in rockfill materials is justified by their inherent flexibility, adaptability to various structures and conditions and capacity to absorb strong seismic shakings [1].

Rockfill behaviour was investigated in the past by several authors involved in the design of rockfill structures [2-4]. The experimental researches developed in the 1970s provided a good overall understanding of the rockfill mechanical behaviour. Tests were conducted with the purpose of obtaining insight on the main factors affecting their shear strength and compressibility. It was realized, for instance, that it is not possible to define a single normal compression line. Pestana e Whittle [5] suggest a model that provides for the convergence to very high stresses of all the curves towards a single final condition (Limit Compression Curve, LCC) governed by the particle breakage and dependent on their mineral composition. Moreover, several authors [6-7] showed that flooding rockfill specimens subjected to onedimensional compression lead to a sudden settlement (volumetric collapse) attributed also to the breakage of particles due to rock weakening induced by wetting.

In recent years, testing programs involved large laboratory equipment have investigated the particle breakage in more detail [8-9]. These authors elaborated that the rate of crack propagation depends on the stress intensity factor $(\mathrm{K})$ characterizing the stress field near the crack tip in the linear elastic fracture mechanics framework. The stress intensity factor $(\mathrm{K})$ is a function of applied stress, geometry of the problem, the length of crack and the loading mode. When a load increment is applied to rockfill, particle cracks with stress intensity factors higher than a critical value (fracture toughness $\mathrm{K}_{\mathrm{C}}$ ) propagate immediately: in this condition particles break and an instantaneous increment of strain at the volume element scale is observed. According to [10] and as elaborated by [8], at vertical stresses smaller than the clastic yield stress, the deformation mechanism is the rearrangement of particles. The clastic yield stress corresponds to the stress level in which the applied load causes the onset of particle crushing. As observed in [57-8], the vertical stress-strain curve is linear above the clastic yield and within the typical rockfill dam vertical stress range.

In this framework, the paper shows the results of oedometric tests performed in a large apparatus designed to test coarse soils. The tests have been carried out on two different soils having the same grain size distribution, very different particle crushing strengths and different initial void index but the same relative density $\left(D_{R}\right)$. The experimental results showed that the mechanical response of rockfill materials is influenced by several factors such as degree of saturation, grain strength and void index. In this study, the influence of individual rock particle strength was taken into account by grain crushing test performed on dry and saturated

Corresponding author: roberta.ventini@unina.it 
particles. Results of oedometric tests performed on specimens prepared with different initial degree of saturation and saturated during the tests are also discussed.

\section{Experimental set-up and procedure}

\subsection{The apparatus}

A large-scale soft oedometer was used to test rockfill materials. The ring adopted is a steel $\left(\mathrm{E}_{\mathrm{R}}=2.1 \cdot 10^{5} \mathrm{MPa}\right)$ cylinder with thickness $t=5 \mathrm{~mm}$ (Fig. 1). The apparatus allows to perform tests on cylindrical specimens with height $\mathrm{H}=25 \mathrm{~cm}$ and diameter $\mathrm{D}=49 \mathrm{~cm}$, confined at the top and the bottom by two grooved still plates.

The vertical load is applied by a hydraulic jack and measured with a load cell on the top of the specimen. The loading-unloading phases were carried out by means of a hydraulic pump. The maximum applied stress at the top of the specimens is $\sigma_{\mathrm{v}}^{\prime}=2.5 \mathrm{MPa}$. The vertical displacement of the specimens is measured with three LVDTs $( \pm 3$ ' stroke, $0.3 \%$ accuracy) placed on the loading cap.

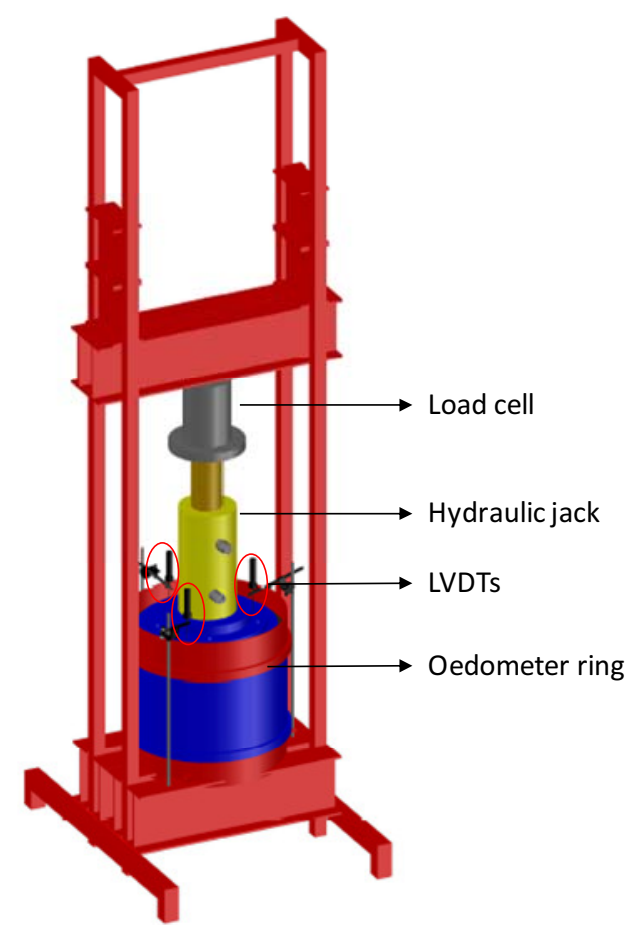

Fig. 1. Large size oedometer apparatus

In truly oedometric conditions, radial strains are nil (i.e. $\varepsilon_{\mathrm{r}}=0$ ) and hence $\varepsilon_{\mathrm{v}}=\varepsilon_{\mathrm{a}}$. In the case of the soft oedometer, radial strain is very small but not nil. In this work, the effect of oedometric ring deformability on the stress state is quantified in the framework of elastoplasticity. The error caused by the unavoidable differences between the experimental and a truly onedimensional strain history caused by ring deformability has been determined as proposed by [11] and has been proven negligible.

\subsection{Materials used and testing programme}

Two coarse-grained soils having the same grading (Fig. 2) but different geological origin were selected for the experimental programme.

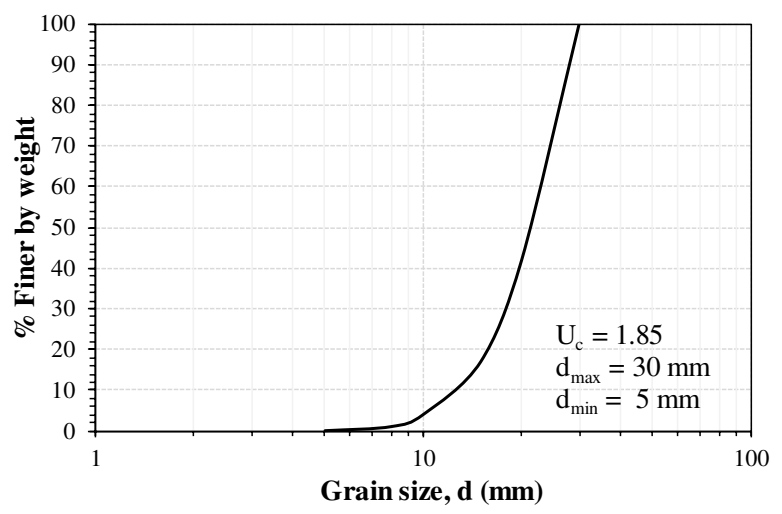

Fig. 2. Grain size distribution adopted for both Coreno and Redisole rockfills

The first one is a limestone rock (Fig. 3a) with low grain porosity coming from a quarry in Coreno Ausonio (Italy). It is first extracted by blasting and then crushed to the desired size. It consists of particles with sharp edges and a specific gravity $\mathrm{G}_{\mathrm{s}}=2.76$. The grains exhibit a high superficial roughness, regular sizes and no dominant dimensions - particle splitting on loading is likely to be small with this rockfill.

The second material tested (Fig. 3b) is a heterogeneous rock obtained from Fiumarella River and used to build the Redisole Dam (Italy), a rockfill upstream faced dam having a height of $40.4 \mathrm{~m}$ and mainly used for irrigation purposes. The mineralogical composition of this rock includes quartz, muscovite, calcite and dolomite. The tested soil, highly fractured, has a specific gravity $\mathrm{G}_{\mathrm{s}}=2.68$. Moreover, particle shape is elongated and planar. This shape is expected to favour particle splitting. This material was obtained in situ, further crushed in the laboratory and sieved.

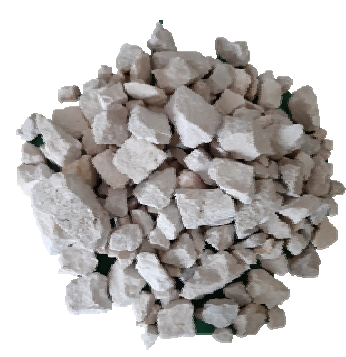

a)

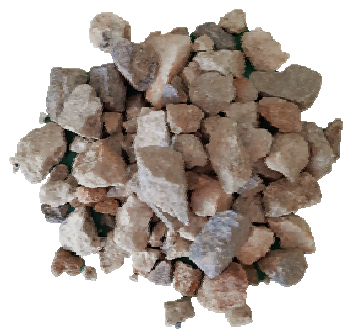

b)
Fig. 3. Tested material: a) Coreno rockfill (C); b) Redisole rockfill $(\mathrm{R})$.

The materials previously dried in a stone at $105{ }^{\circ} \mathrm{C}$ were used to prepare the specimens directly in the oedometer ring and were compacted in five equal layers having thickness of $5 \mathrm{~cm}$, using a vibrating table with a frequency of $60 \mathrm{~Hz}$. The procedure was established after 
several trials to get the required initial relative density $D_{r}$ $=0.70$.

The experimental programme involved three series of tests for each rockfill type. The first one was performed under fully saturated conditions: once compacted, specimens were saturated and then compressed. In the second series, specimens compacted in an identical manner were maintained at ambient relative humidity during all the oedometric test. In the third series dry specimens were saturated during the oedometric test, after the application of a vertical load $\sigma_{\mathrm{v}}^{\prime}=1000 \mathrm{kPa}$. A summary of the testing programme is reported in Table 1.

Table 1. Experimental programme.

\begin{tabular}{|c|c|c|c|c|c|c|c|}
\hline Rockfill & $\begin{array}{l}\text { ID } \\
\text { test }\end{array}$ & $\begin{array}{c}\mathrm{D}_{\mathrm{r}} \\
-\end{array}$ & $\begin{array}{c}\mathrm{e}_{\min } \\
-\end{array}$ & $\begin{array}{c}\mathrm{e}_{\max } \\
-\end{array}$ & $\begin{array}{l}\mathrm{e}_{0} \\
-\end{array}$ & $\begin{array}{c}S_{r, 0} \\
-\end{array}$ & $\begin{array}{r}S_{r, f} \\
-\end{array}$ \\
\hline \multirow{3}{*}{ Coreno } & $\mathrm{CU}$ & \multirow{6}{*}{0.70} & \multirow{3}{*}{0.610} & \multirow{3}{*}{0.900} & \multirow{3}{*}{0.697} & 0 & 0 \\
\hline & CUS & & & & & 0 & 1 \\
\hline & $\mathrm{CS}$ & & & & & 1 & 1 \\
\hline \multirow{3}{*}{ Redisole } & RU & & \multirow{3}{*}{0.659} & \multirow{3}{*}{0.862} & \multirow{3}{*}{0.720} & 0 & 0 \\
\hline & RUS & & & & & 0 & 1 \\
\hline & RS & & & & & 1 & 1 \\
\hline
\end{tabular}

\subsection{Grain crushing tests}

As stated before, particle breakage plays an important role in rockfill behaviour. In fact, the tensile strength of grains influences the mechanical response of an aggregate. In the past many efforts have been made to relate the micromechanics of grain fracture to the macroscopic deformation of crushable aggregate.

It is widely recognized in literature that the failure of a spherical particle under compression is a tensile failure. Therefore, the tensile strength of rock grains can be indirectly measured by diametrical compression between flat platens [12]. For this reason, the single particle crushing strength was determined in this work using the procedure suggested by [13] and [14] with a test set-up shown in Figure 4a. Unconfined crushing tests were carried out on groups of three grains placed between two rigid and smooth steel plates, and then moving the lower plate at a constant displacement rate. The upper plate and the load cell connected to it were fixed. The load measuring capacity was $20 \mathrm{kN}$ with a resolution of $0.01 \mathrm{~N}$. A displacement rate of 0.01 $\mathrm{mm} / \mathrm{min}$ was imposed. During the tests, the applied forces $\mathrm{P}$ were measured by load cell while the displacements were calculated starting from the recorded times on the basis of the displacement rate.

The three grains were chosen of similar size and placed on the plate so as to have a minimum number of contacts with the upper plate. This was possible thanks to the fact that all the materials used had grains with sharp edges, and it was therefore possible to find some grain that had almost continuous contact on the lower base and in a few points on the upper base. In this way we are confident that the break occurs at these points.

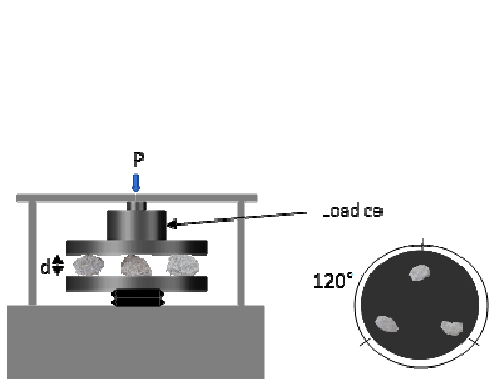

a)

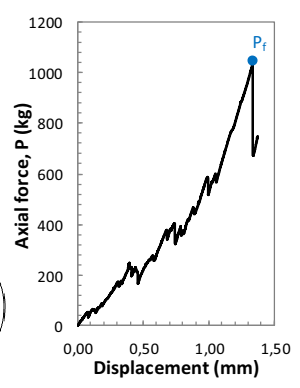

b)
Fig. 4. a) Particle tensile strength test set-up for dry grains; b) Typical load-displacement plot

Before starting the test, the average distance $d$ between the two plates was determined by averaging three measurements at $120^{\circ}$ using a centesimal gauge. This distance was assumed as the characteristic diameter of the grains. Sheets of black carbon copy paper were used to determine the total number of contacts between the particles and the plates, both at the beginning and at the end of the test. The average $\mathrm{N}$ of these two values, was used as a representative value of the number of contacts between particles and plates. This type of measurement is surely affected by some margin of error, but its use is essential for the calculation of the individual particle strength. Furthermore, the experimental results showed a low dispersion.

Finally, a non-secondary problem is represented by the choice of a value of the applied force $P$ to be assumed as a breaking value, $\mathrm{P}_{\mathrm{f}}$. Figure $4 \mathrm{~b}$ shows a typical plot of platen load $\mathrm{P}$ as a function of the platen displacement obtained from these tests. It can be seen that there are some initial peaks in the load-displacement curve, which correspond to the fracturing of asperities and the rounding of the particle. However, this cannot be described as failure of the particle: the asperity under the platen which has just broken off would have fractured irrespective of the size of the parent particle. Therefore, the particle crushing takes place progressively and in theory could continue until they are pulverized. If the test did not stop, the load would continue to grow steadily after all the peaks exhibited.

In order to determine the tensile strength of grains it was decided to use the solution proposed by [13]. He calculated the tensile strength of grains as:

$$
p_{\mathrm{f}}=\mathrm{P}_{\mathrm{f}} /\left(\mathrm{N} \cdot \mathrm{d}^{2}\right)
$$

where the subscript $f$ denotes failure. The failure condition is that for which a fragment weighing more than $25 \%$ of the original grain is detached from a grain.

It can be clearly seen in Figure $4 \mathrm{~b}$ that the initial small peaks are followed by a large peak corresponding to the maximum load, and a catastrophic failure as the 
particle splits and the load drops dramatically. Particle fracture is interpreted as particle 'splitting'.

Lee [14] found that for particles of a given size and mineralogy, the tensile strength is not a constant but has a standard deviation about some mean value. Furthermore, he found the average tensile strength to be a function of particle size $\mathrm{d}$ :

$$
p_{\mathrm{f}}=\chi \cdot \mathrm{d}^{\omega-2}
$$

where $\chi$ and $\omega$ are constants dependent on the material.

The tests have been performed both on dry and saturated grains. In this second case the grains were previously placed in a closed vessel filled with pressurised water (Fig. 5).

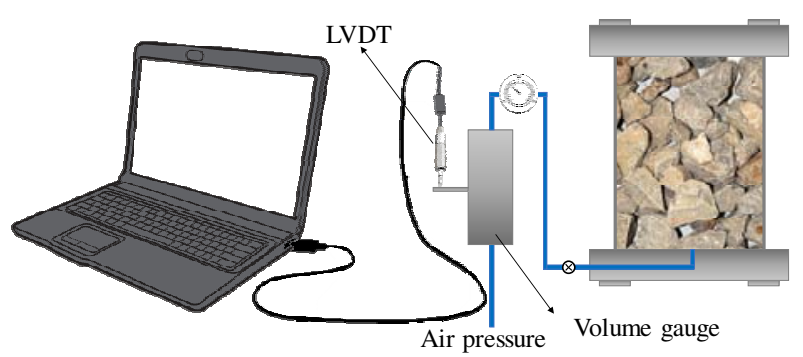

Fig. 5. System used to saturate grains

The water pressure in the vessel was kept constant at $70 \mathrm{kPa}$. Through an external volume gauge connected to the vessel, the volumes of water absorbed by the grains were estimated. The grains were kept in the vessel until the absorbed volume-time curve approached its horizontal asymptote. This procedure aims to completely saturate the pores of the grain. The grains saturated as described were subjected to crushing tests using the system already shown in Figure $4 \mathrm{a}$, with the only difference that the saturated grains were kept in water during the crushing test.

Two series of tests were carried out, respectively on dry and saturated grains. Each series includes 10 tests on Coreno rockfill and 10 tests on Redisole rockfill. The results are shown in Figure 6.

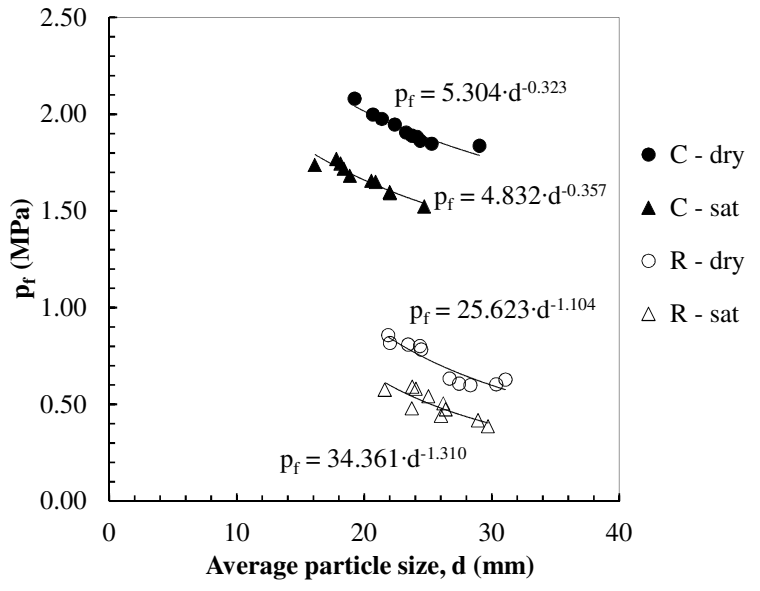

Fig. 6. Results of grain crushing tests
According to literature, $\mathrm{p}_{\mathrm{f}}$ decreases as the diameter increases for both materials, both for dry and saturated grains. The obtained regressions are shown in the Figure 6 . In order to compare the two materials and therefore to verify the influence of the degree of saturation, the values of $\mathrm{p}_{\mathrm{f}}$ obtained considering the diameter $\mathrm{d}_{50}(=21.4$ $\mathrm{mm}$ ) of the adopted grain size distribution curve are reported in Table 2. The data highlight that (a) Redisole grains have a lower tensile strength than Coreno ones and (b) saturated grains have a lower strength than dry ones.

Table 2. Particle strength assumed for the adopted grain size distribution.

\begin{tabular}{|c|c|c|}
\hline \multirow{2}{*}{ Rockfill } & $\mathrm{S}_{\mathrm{r}, \text { grains }}$ & $\mathrm{p}_{\mathrm{f}}$ \\
& - & $\mathrm{MPa}$ \\
\hline \multirow{2}{*}{ Coreno } & 0 & 1.97 \\
\cline { 2 - 3 } & 1 & 1.62 \\
\hline \multirow{2}{*}{ Redisole } & 0 & 0.87 \\
\cline { 2 - 3 } & 1 & 0.62 \\
\hline
\end{tabular}

\section{Oedometric test results}

Figures 7 and 8 show the results of oedometric tests in terms of void index versus the applied vertical stress - in semi-logarithmic scale - for Coreno and Redisole rockfill. Specimens of Coreno rockfill have similar compressibility, regardless of the initial degree of saturation (Fig. 7). Moreover, for high stress, the curves merge into a single line. It can also be seen that a moderate collapse was recorded during flooding (CUS test). It would seem that there is no influence of saturation in the post-yield region.

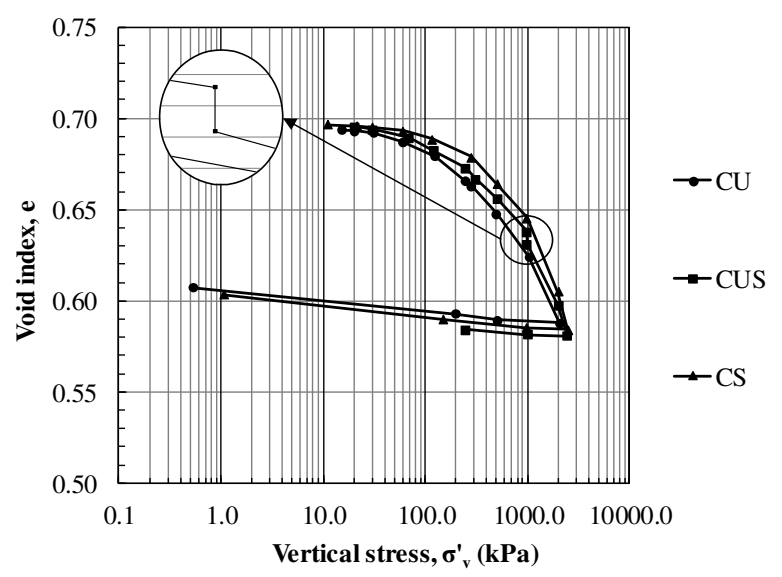

Fig. 7. Results of one-dimensional compression test on Coreno rockfill with a zoom of the saturation phase

On the contrary, the test results on Redisole rockfill (Fig. 8) show the remarkable effect of the degree of 
saturation on the material behaviour: the dry specimen is less compressible than the saturated one. Furthermore, a sudden additional crushing upon wetting is evident (RUS test). The amount of collapse strain was very close to the strain difference between the normal compression lines corresponding to the initial water content (dry state) and the saturated state. The subsequent loading after collapse leads to a curve that follows the normal compression line for the saturated material. It is interesting to note that the volume change behaviours of the two rockfill materials with the same grain size distribution are significantly different from each other. Redisole material is more compressible than Coreno rockfill and this is probably due to the greater particle strength of the Coreno grains (Table 2).

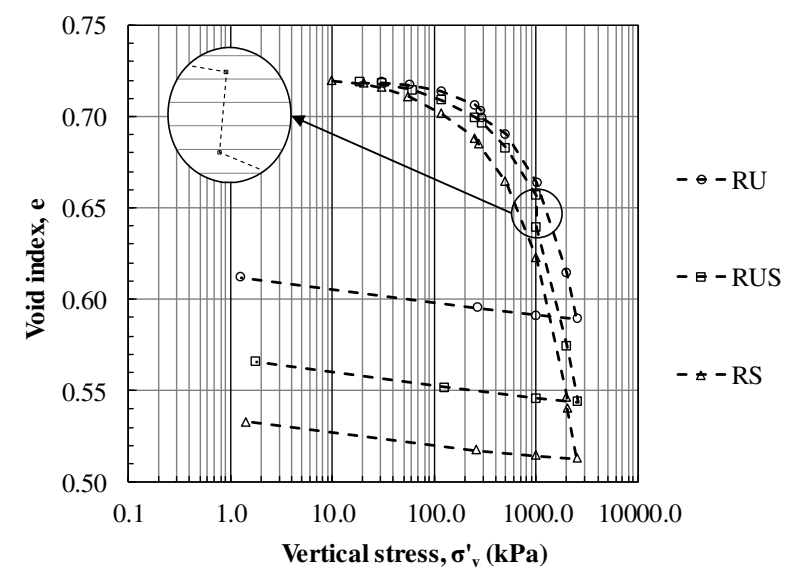

Fig. 8. Results of one-dimensional compression test on Redisole rockfill with a zoom of the saturation phase

The degree of saturation has also an effect on the particle crushing that can be expressed quantitatively by the breakage factor $B_{g}$ [15] defined as the sum of decreases (or increases) in the percentage of particles retained on a standard sieves series.

It is noted in Figure 9 that the breakage factor increases for saturated specimens and it is always greater for Redisole rockfill. It is also significant to note that the effect of the degree of saturation is more pronounced for the Redisole material than the Coreno one, whose filled black points lie closer together. Furthermore, $\mathrm{B}_{\mathrm{g}}$ increased with increase in initial void ratio.

The particle crushing has been evaluated from the change in the grain size distributions prior to and after testing, showing a significant increase in the fines, not present in the original soil, as a result of the breaking of asperities and a greater particle breakage undergone by Redisole rockfill (Fig. 10). This could influence both the mechanical behaviour and the permeability of the material.

The relationship between the compressibility index $\mathrm{C}_{\mathrm{c}}$ and the breakage factor $\mathrm{B}_{\mathrm{g}}$ is reported in Figure 11 . As well known, $\mathrm{C}_{\mathrm{c}}$ increases with particle crushing. Figure 11 also shows the influence of the degree of saturation. The value of $\mathrm{C}_{\mathrm{c}}$ is higher as the degree of saturation increase. This highlight that the effect of water on compressibility and particle breakage cannot be overlooked.

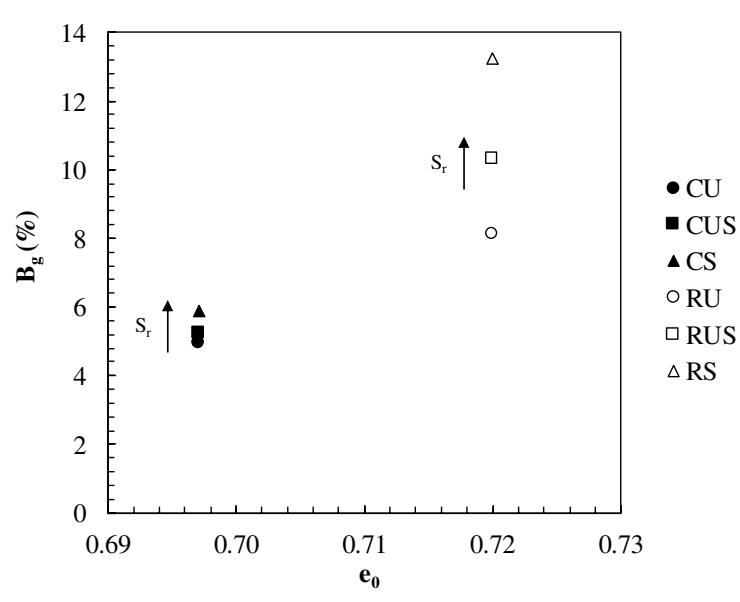

Fig. 9. Relationship between the breakage factor and initial void index

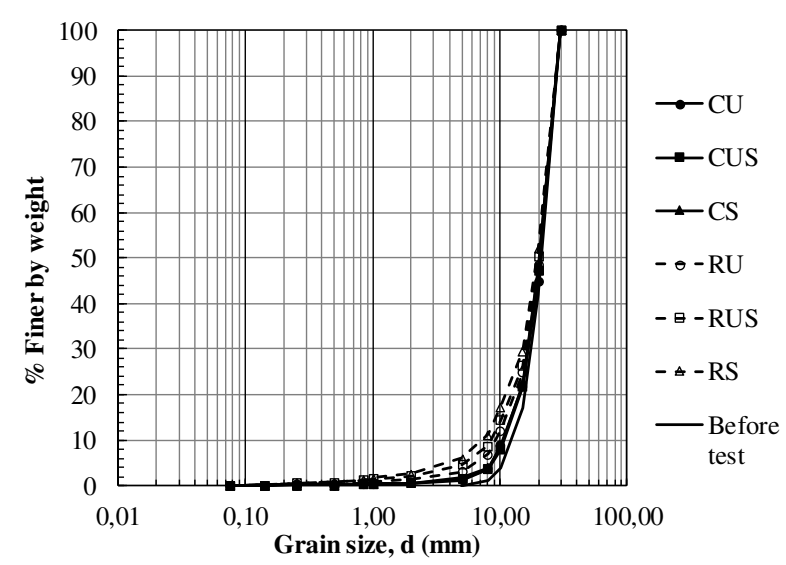

Fig. 10. Grain size distributions prior to and after testing

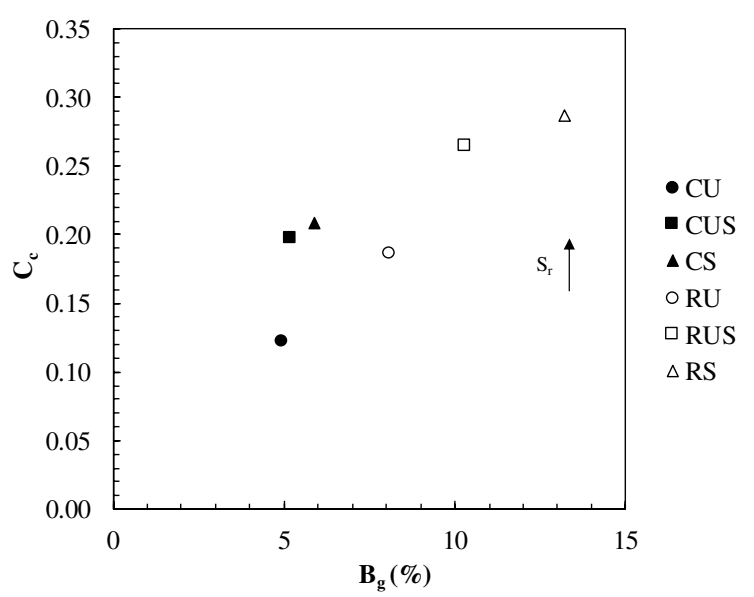

Fig. 11. Variation of compressibility index with breakage factor for Coreno and Redisole rockfill

The high values of the breakage factors in the Redisole material are also due to the relatively low strength of the particles (Table 2). In Figure 12 the normalized void index is plotted against the vertical stress normalized with the average tensile strength $\mathrm{p}_{\mathrm{f}}$. It is shown that the stress ratio $\sigma^{\prime}{ }_{\mathrm{v}} / \mathrm{p}_{\mathrm{f}}$ is always greater for Redisole rockfill and for greater degree of saturation, as 
expected. This confirms the effect of average particle tensile strength on rockfill compressibility.

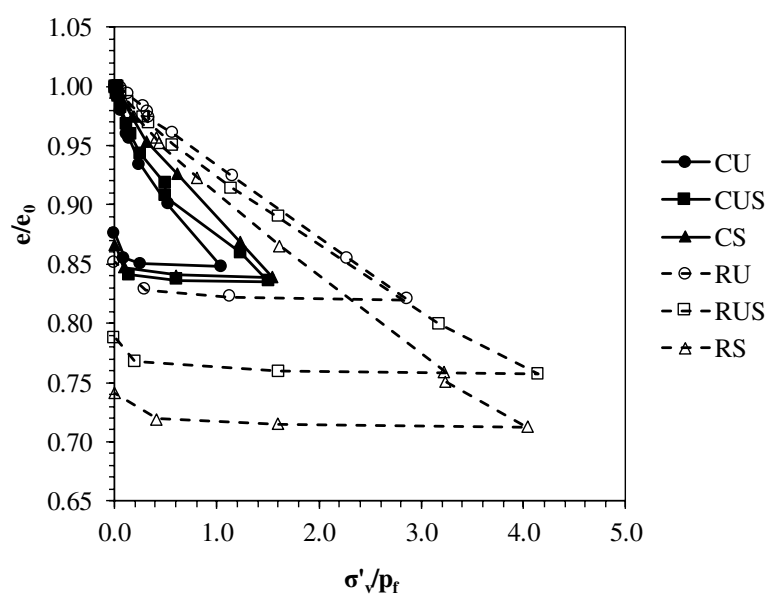

Fig. 12. Relationship between the normalized void index and stress ratio $\sigma_{\mathrm{v}} / \mathrm{p}_{\mathrm{f}}$

\section{Concluding remarks}

Oedometer tests have been carried out on rockfill materials obtained from two different sites but with the same grain size distribution. Grain crushing tests are also presented and discussed. It emerged that saturated grains have a lower strength and the calcareous particles are less prone to break than the other ones.

The experimental results of one-dimensional compression tests show a lower compressibility of rockfill with greater single particle strength that exhibit a void index-vertical stress that seems to be independent of the initial degree of saturation. On the contrary the more crushable rockfill is more compressible and exhibits different strains to vary of the degree of saturation. Furthermore, saturated specimen leads to a collapse strain equal to that observed in wetting for rockfill with a lower particle strength.

Generally speaking, the tests results show the effect of the degree of saturation on the material behaviour. It influences both compressibility and particle breakage.

The material used in this test programme perform as observed in previously published experimental data so the results confirm that any situation leading to a change in degree of saturation of the rock particles could cause collapse deformations and increase particle breakage. Moreover, the effect of the degree of saturation is essential to predict the behaviour of rockfill structures.

\section{Acknowledgements}

The authors gratefully acknowledge the support given by the student Gianluigi Illiano during the research work reported in this paper.

\section{References}

1. A. K. Gupta, Effects of particle size and confining pressure on breakage factor of rockfill materials using medium triaxial test, J. of Rock Mechanics and Geotech. Engrg., 8, 3, 378-388 (2016)

2. E. Fumagalli, Tests on cohesionless materials for rockfill dams, J. of the Soil Mechanics and Foundations Division, ASCE, 95, 1, 313-332 (1969)

3. N. D. Marachi, C. K. Chan, H. B. Seed, J. M. Duncan, Strength and deformation characteristics of rockfill materials, Dep. of Civil Engrg., Report No. TE-69-5. University of California (1969)

4. R. J. Marsal, Mechanical properties of rockfill. Embankment Dam Engineering, Casagrande Volume, Wiley, New York, 109-200 (1973)

5. J. M. Pestana, A. J. Whittle, Compression model for cohesionless soils, Géotechnique, 45, 4, 611-631 (1995)

6. G. F. Sowers, R. C. Williams, T. S. Wallace, Compressibility of broken rock and settlement of rockfills, Proc. of 6th ICSMFE. Montreal, 2, 561565 (1965)

7. E. S. Nobari, J. M. Duncan, Effect of reservoir filling on stresses and movements in earth and rockfill dams, Dep. of Civil Engrg., Report No. TE72-1, University of California (1972)

8. L. A. Oldecop, E. E. Alonso, A model for rockfill compressibility, Géotechnique, 51, 2, 127-140 (2001)

9. L. A. Oldecop, E. E. Alonso, Theoretical investigation of the time-dependent behavior of rockfill, Géotechnique, 57, 3, 289-301 (2007)

10. G. R. McDowell, M. D. Bolton, On the micromechanics of crushable aggregates, Géotechnique, 48, 5, 667-679 (1998)

11. S. Lirer, A. Flora, M. V. Nicotera, Some remarks on the coefficient of earth pressure at rest in compacted sandy gravel, Acta Geotechinica, 6, 1, 1-12 (2011)

12. J. C. Jaeger, Failure of rocks under tensile conditions, Int. J. Rock. Min. Sci., 4, 219-227 (1967)

13. J. Billiam, Some aspects of the behaviour of granular material at high pressures, Proc. of Roscoe Memorial Symposium on Stress-Strain Behaviour of Soils, Cambridge University, 69-80 (1967)

14. D. M. Lee, The angles of friction of granular fills, Ph.D. dissertation, University of Cambridge (1992)

15. R. J. Marsal, Large scale testing of rockfill materials, J. SMFE, ASCE, 93, 2, 27-43 (1967) 